\title{
Urinary Lithiases: Epidemiological, Clinical and Therapeutic Aspects of 164 Cases at Sheikh Zayed Hospital in Nouakchott-Mauritania
}

\author{
Mouhamedou Diagana, Yahya Tfeil, Mohamed Mahmoud Boya, Mohamed Essalem Béchir \\ Faculty of Medicine, Sheikh Zayed Hospital, Al Assriya University, Nouakchott, Mauritania \\ Email:bagdiagana@yahoo.fr, tefeil2000@gmail.com,mahmoudboya@gmail.com, bechirely@gmail.com
}

How to cite this paper: Diagana, M., Tfeil, Y., Boya, M.M. and Béchir, M.E. (2020) Urinary Lithiases: Epidemiological, Clinical and Therapeutic Aspects of 164 Cases at Sheikh Zayed Hospital in NouakchottMauritania. Open Journal of Urology, 10, 217-224.

https://doi.org/10.4236/oju.2020.107025

Received: May 8, 2020

Accepted: July 11, 2020

Published: July 14, 2020

Copyright $\odot 2020$ by author(s) and Scientific Research Publishing Inc. This work is licensed under the Creative Commons Attribution International License (CC BY 4.0).

http://creativecommons.org/licenses/by/4.0/

(c) (i) Open Access

\begin{abstract}
Urinary lithiases occupy an important position with respect to urological activities in our department. In our Sahel region, lithiasic pathology represents $40 \%$ in urology in Senegal [1]. In Mauritania, we did not find a study evaluating the prevalence of this pathology. The frequency and gravity are variable. The objective of the study was to report the clinical profile and the results of management of urinary lithiasis in our environment. Materials and Methods: We conducted a retrospective, descriptive study spanning over two years (April 2015 to March 2017) in the urology department of Sheikh Zayed Hospital in Nouakchott. All patients operated for urinary lithiasis during this period were included in the study. The operative techniques used were semi rigid ureteroscopy, extra corporeal lithotrity, open surgery. Our center did not have flexible ureteroscopy and percutaneous nephrolithotomy. The indications were lithotrity for calculations lower than $20 \mathrm{~mm}$ of low density. Biger than $20 \mathrm{~mm}$ were by open surgery. Semi rigid ureteroscopy for distal ureteral calculi. Medical treatment or monitoring for non-obstructive calculi is less than $7 \mathrm{~mm}$. Urine drainage by jj probe or nephrostomy are performed. We excluded all patients with lithiasis for the medical treatment. The result was good when absence of lithiasis residues was less than $7 \mathrm{~mm}$ and removal of the obstruction. Results: A total of 164 patients were found. The average age was 41 years, and F/M ratio was $1 / 10$. Considering geographical origin, $82 \%$ of patients came from rural areas. The presenting complaint was mainly Lower Urinary Tract Symptoms (56\%) and Renal Colicky Pain (31\%). The bladder and kidneys were the most common (respective $45 \%$ and $35 \%$ ) sites of stone location. Bilateral stones were $18 \%$. Staghorn stones constituted $6 \%$ of the cases. Non steroidal anti-inflammatory treatment was administered in $82 \%$ of cases, while antibiotic therapy was administered in $32 \%$ of cases. Complications occurred in open surgery about $11 \%$ like parietal infection and
\end{abstract}


residual stones. $0.6 \%$ of ESWL got uretere obstruction that needed $\mathrm{jj}$ catheter. $4 \%$ of cystolithotomy had infection. Conclusion: Urinary lithiasis often consults at the complication stage. Minimally invasive techniques are limited in our service and offer less complication.

\section{Keywords}

Lithiasis, Urinary

\section{Introduction}

The epidemiological and therapeutic profile of urinary lithiasis depends on several factors including socioeconomic status of the country, level of medical care and climatic conditions [1]. This profile undergoes constant change. In Mauritania, few data is available on urinary lithiasis, which has an important place in the urologic activities carried out in our department. In our Sahel region, lithiasic pathology represents $40 \%$ in urology activity in Senegal [1]. Localization of stone is diverse and the treatment modalities are rapidly changing with technological evolution. The objective of our study was to report the clinical profile and the results of management of urinary lithiasis in our context.

\section{Patients and Methods}

We conducted a two-year retrospective study between April 2015 and March 2017 in the urology department of the Sheikh Zayed Hospital in Nouakchott. Our department has a small capacity of 12 beds, three urologists, and one resident. It is situated at the outskirts of Nouakchott with a high population density. All patients operated in our unit were included in the study. Diagnostic methods were uroscaner for lithiasis of the upper urinary tract. Ultrasound coupled with conventional radiology in bladder stones. The operative techniques used were semi rigid ureteroscopy, extra corporeal lithotrithy, open surgery. Our center did not have flexible ureteroscopy and percutaneous nephrolithomy. The indications were lithotrithy for calculations lower than $20 \mathrm{~mm}$ of low density. Bigger than 20 $\mathrm{mm}$ were by open surgery. Semi rigid urestroscopy for distal ureteral calculi. Medical treatment or monitoring for non-obstructive calculi and less than 7 $\mathrm{mm}$. urine drainage by jj probe or nephrostomy are performed. We excluded all patients with stones treated medically. The result was good when absence of lithiasis residues less than $7 \mathrm{~mm}$ and removal of the obstruction Parameters studied was, age, localization, obstruction, choice of treatment, complications. Statistics analysis was IPSS.

\section{Results}

We treated 164 cases of urinary lithiasis, which represent of $28.1 \%$ of all patients operated in our department, and these involved several localizations of the uri- 
nary system. The bladder (45\%) and kidneys (35\%) were the most frequent localizations (Figure 1). The mean age was 41 years and ranged from 2 to 84 years. The majority were in the range 20 - 40 years age with $43.9 \%$ of cases (Figure 2). The F/M ratio was $1 / 10$. For geographical origin, $82 \%$ of patients came from rural area. The presenting complaints were mostly renal colicky pains (31\%) and lower Urinary Tract Symptoms (52\%) of cases were incidentally discovered during routine analysis (Table 1, Figure 1). Biological complications were found in $35 \%$ of cases (anemia, high creatinin); three of them were in chronic renal failure currently undergoing dialysis for renal parenchyma laminated following obstruction. Dilatation of the urinary tracts was observed in $37 \%$ of cases. Localization was bilateral in $18 \%$ of cases. Staghorn stone was found in $6 \%$ of cases (Figure 3 and Figure 4), and one patient had the bladder completely filled

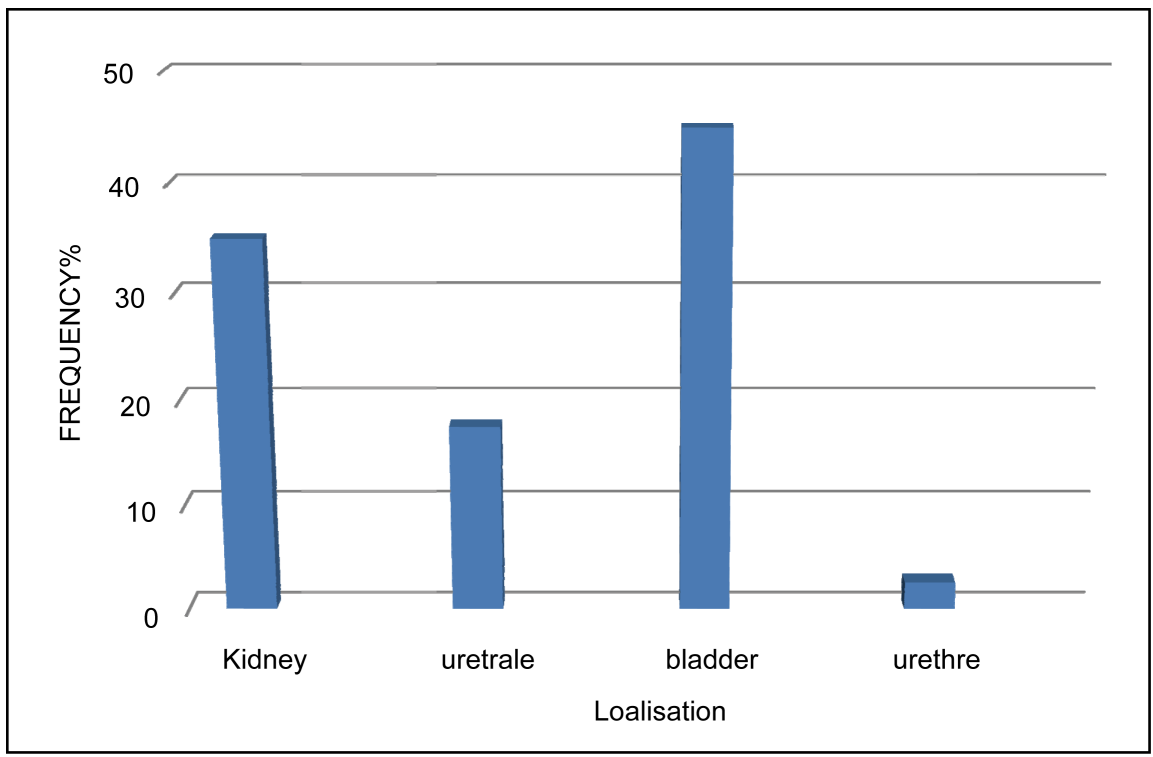

Figure 1. Localization of the stones in the urinary tract.

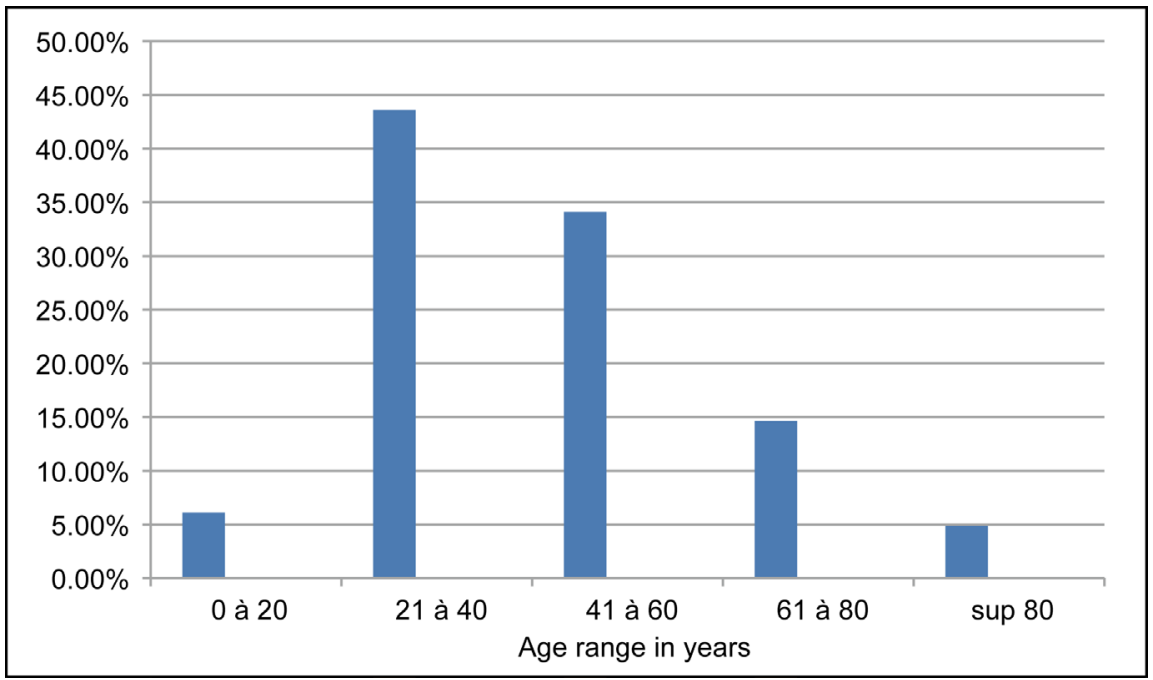

Figure 2. Distribution of patients according to age. 
with a huge stone with severe bilateral uretero pyelocaliceal dilatation. The etiology of the stone was unknown in $48 \%$, metabolic analysis for stone necessary for determine etiology. Bladder neck and prostatic obstruction in 35\%, urethral stricture $10 \%$, and ureteropelvic junction obstruction in $3.75 \%$ of cases. Urethral stricture and bladder neck contracture were the etiological factors associated with the huge stone which completely filled the bladder in one patient. The stone extracted weighed $480 \mathrm{~g}$. (Figure 5). Before surgery, 38.7\% of patients had received antibiotic treatment, specifically quinolones. Antibiotic therapy based on

Table 1. Distribution of patients according to presenting complaint.

\begin{tabular}{cccccc}
\hline $\begin{array}{c}\text { Renal colicky } \\
\text { pains }\end{array}$ & $\begin{array}{c}\text { Lower Urinary } \\
\text { Tract Symptoms }\end{array}$ & $\begin{array}{c}\text { Hypogastric } \\
\text { pain }\end{array}$ & Haematuria & $\begin{array}{c}\text { Incidental } \\
\text { finding }\end{array}$ & total \\
\hline $41.2 \%$ & $25 \%$ & $22.5 \%$ & $8.7 \%$ & $2.5 \%$ & $100 \%$ \\
\hline
\end{tabular}

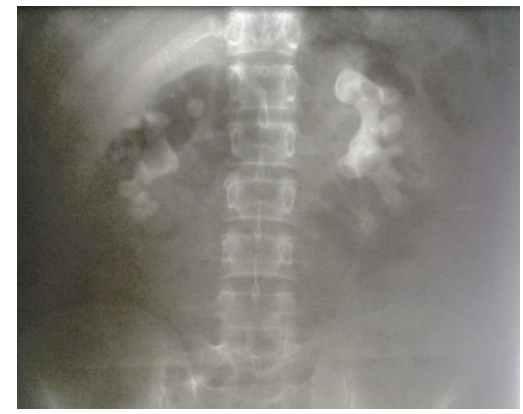

Figure 3. Bilateral radio-opaque staghorn stone on a plain radiograph.

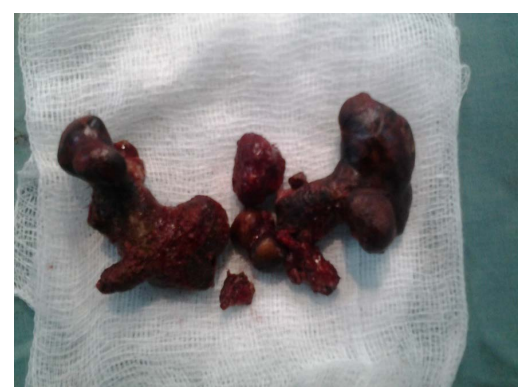

Figure 4. Bilateral staghorn after removal by open surgery.

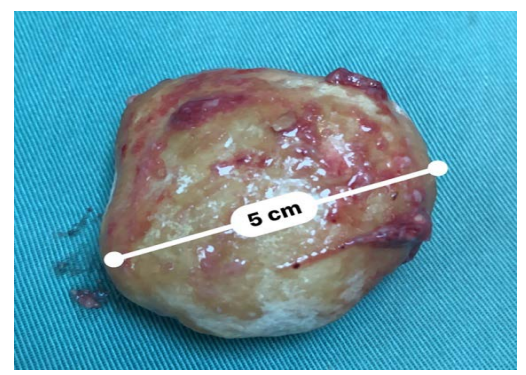

Figure 5. Bladder stone. 
cytobacteriological examing or clinical signs of urinary tract infection Non-steroidal anti-inflammatory drugs were prescribed to $80 \%$ of patients. Anti-inflammatory drugs are prescribed for analgesic purposes and apart from contraindications. Open surgery was performed in $87 \%$ of the patients, while 8 patients we retreated using Extracorporeal Shock Wave Lithotripsy (ESWL).

Postoperative complications included hemorrhage in 2 cases of staghorn stone requiring blood transfusion. Two cases of residual kidney stones were secondarily treated with ESWL. Three patients developed a vesico-cutaneous fistula requiring prolonged bladder drainage and a long hospital stay. Abdominal wall infection was found in $3.7 \%$ of cases.

\section{Discussion}

Urinary stone disease varies according climatic zones, feeding habits and the quality of drinkable water. In Congo, Odzebe [2] reported 68 cases over 4 years and Zoung-K [3] in Cameroon 118 cases over 4 years. Countries in Sahel seem to be more exposed than those in Central African region. In Senegal, Y Tfeil [4] found 30 children with urolithiasis over a 2 -year period. The mean age varies between 30 - 50 years in the literature [5] [6]; Odzebe [2] found a mean age of 53 years. Majority of our patients were young, and age from 20 to 60 year was the mostly affected age range. Sex ratio varies according to different authors F/M 1/8 to $1 / 10$ [4] [7]. Lower urinary tract symptoms were the most frequent presenting complaint followed by renal colicky pains.

The bladder was the common (45\%) site of stone localization in this study. In Cameroon, $42 \%$ of bladder stones against $39 \%$ of renal stones [2]. Ureteral localization is very rare but with the remarkable symptom [8]. staghorm are more frequent in our series, the authors find $01 \%$ to $04 \%$ [9] [10]. Bilateral urinary stones were $21 \%$ to Mali [11].

Imaging investigations usually reveal the diagnosis; ultrasonography usually done as first choice, coupled with plain kidney-ureter-bladder (KUB) radiography and or a computerized tomography urography scan (CTU) were the diagnostic tools in our series and in the literature [12] [13] [14]. Intravenous Urography was rarely requested. Staghorn stone and bilateral stone localization were common and required a search for etiology [15] [16]. There was a patient who presented with a poor general state carrying a huge stone occupying the entire bladder cavity on a urethral stricture. A $480 \mathrm{~g}$ stone adherent to the bladder wall was extracted. the etiological factors were sedentariness, lack of drinking water in rural areas, consumption of red meat; the hot and dry climate of the Sahel. Delay in consultation is an aggravating factor, favoring the occurrence of complications. Medical treatment with Non-steroidal Anti-inflammatory Drugs (NSAID) has been reported to between $48 \%$ to $72 \%$ in some series [17] [18]. Antibiotic treatment is used in cases of fever, cloudy or purulent urine, or positive urine culture [19] [20]. Microorganism commonly encountered includes Proteus, K. Pneumoniae, Staphylococcus and E coli [20]. In current practice, treat- 
ment of urolithiasis is oriented towards minimally invasive techniques including ureteroscopy, ESWL and percutaneous nephrolithotomy (PCNL) [8] [19] [21]. Open surgery is reserved for some complex stones [22]. In our context, open surgery still has a major role due to the lack of minimally invasive equipments. All types of urinary drainage techniques were used in our series in emergency. Drainage in cases of obstruction was performed as a means of relief while awaiting surgery [23]. Hemorrhagic complications following conventional open surgery are reported to be rare in the literature [18] [24]. Vesicocutaneous fistula and wound infections are common, attributable to urine infection complicating urolithiasis [18] [25]. Postoperative drainage could be maintained until the urinary tract is completely sealed [25].

\section{Conclusions}

Urolithiasis is common in Mauritania, a country located in Sahel region, which is hot and dry. The quality of drinkable water is below standard in certain parts of the country. The feeding habits are based on red meat essentially, and a sedentary life style is some factors which favour the occurrence of stone.

Delay ance before consultation and the absence of imaging equipments in all the cities could account for the occurrence of complex stones and the frequency of functional renal complications. Stone disease could be prevented by improving hygiene and dietary life style measures, curable by the development of non or minimally invasive therapeutic modalities.

\section{Conflicts of Interest}

The authors declare no conflicts of interest regarding the publication of this paper.

\section{References}

[1] Diallo, Y., Kouka, S.C. and Kane, R. (2015) Lithiase du haut appareil urinaire: Aspects épidemiologiques, cliniques et thérapeutiques dans la région de Thiés, Sénégal. La Revue Médicale de Madagascar, 5, 520-525.

[2] Odzebe, A.W.S., Boya, P.A. and Koutaba, E. (2015) Lithiase urinaire chez l'enfant au centre hospitalo universitaire de Brazzaville. Uro' andro, 1, 183-187.

[3] Zoung-Kanyi, J. and Sow, M. (1990) Lithiases urinaire au Cameroun: Considerations étiopathogéniques, cliniques et thérapeutiques. Medecine $d$ Afrique Noire, 37, 176-182.

[4] Tfeil, Y. (2016) Lithiases vésicale chez l'enfant à propos de 30 cas en Mauritanie. Uro' andro, 1, 279-282.

[5] Calestrouat, J.P., Djelouat, T. and Costa, P. (2010) Manifestations cliniques de la lithiase urinaire. EMC-Urologie, 28, 1-10. https://doi.org/10.1016/S1762-0953(10)50611-3

[6] Djelloul, Z., Djelloul, A., Bedjaoui, A., et al. (2006) Lithiase urinaire dans l'ouest algérien: Étude de la composition de 1354 calculs urinaires en relation avec leur localisation anatomique, l'âge et le sexe des patients. Progrès en Urologie, 16, 328-335. 
[7] Laziri, F., Rhazifilali, F. and Amchhoud, I. (2009) Etude rétrospective de la lithiase urinaire à l'Hôpital Hassan II de la province de Settat (Maroc). African Journal of Urology, 15, 117-123. https://doi.org/10.1007/s12301-009-0028-1

[8] Kambou, T., Traoré, A.C., Zango, B., et al. (2005) La lithiase du haut appareil urinaire au centre hospitalier universitaire SanouSouro de Bobo-Dioulasso (Burkina Faso): Aspects épidémiologiques, cliniques et thérapeutiques, à propos de 110 cas. African Journal of Urology, 11, 55-60.

[9] Boudeyer, T.I., Adelsalem, A. and Sidahmed, M., et al. (2018) Profil morpho constitutionnel de la lithiase urinaire en Mauritanie. International Journal of Advanced Research, 6, 24-32.

[10] Saussine, C., Lechevallier, E. and Traxer, O. (2008) Calculs et anomalies urétérales. Progrès en Urologie, 18, 997-999. https://doi.org/10.1016/j.purol.2008.09.001

[11] Ouattara, Z., Effoe, A.D., Tembely, A., et al. (2004) Etude de 72 cas de lithiase du haut appareil urinaire au service d'urologie de l'hôpital du point G. Le Mali Médical, 19, 1-3.

[12] Bagga, H.S., Chi, T., Miller, J., et al. (2013) New Insights into the Pathogenesis of Renal Calculi. Urologic Clinics of North America, 40, 1-12. https://doi.org/10.1016/j.ucl.2012.09.006

[13] Haymann, J.P. (2008) Le syndrome métabolique: Facteur de risque de la maladie lithiasique. Progrès en Urologie, 18, 22-24. https://doi.org/10.1016/S1761-676X(08)70014-2

[14] Traxer, O., Lechevallier, E. and Saussine, C. (2008) Bilan métabolique d'un patient lithiasique: Le rôle de l'urologue. Progrès en Urologie, 18, 849-856. https://doi.org/10.1016/j.purol.2008.09.042

[15] Zerifi, R., Bahlous, A., Marakchi, O., et al. (2008) Syndrome métabolique: Physiopathologie et impact sur la lithogenèse. Annales de Biologie Clinique, 66, 9-17.

[16] Conort, P. and Tostivint, I. (2011) Conduite à tenir lors de la découverte d'un calcul urinaire. Revue du Praticien, 61, 379-381.

[17] Sebe, P., Traxer, O., Lechevallier, E., et al. (2008) Anatomie morphologique de la voie excrétrice supérieure intrarénale: Considérations anatomiques appliquées à l'endo-urologie. Progrès en Urologie, 18, 837-840. https://doi.org/10.1016/j.purol.2008.09.039

[18] Lechevallier, E., Saussine, C. and Traxer, O. (2008) Imagerie et calcul de la voie excrétrice urinaire supérieure. Progrès en Urologie, 18, 863-867. https://doi.org/10.1016/j.purol.2008.09.014

[19] Daudon, M., Bounxouei, B., Santa Cruz, F., et al. (2004) Composition des calculs observés aujourd'hui dans les pays non industrialisés. Progrès en Urologie, 14, 1151-1161.

[20] Sow, Y., Fall, B., Sarr, A., et al. (2011) Pyonéphrose: 44 observations au Sénégal. Med Trop, 71, 495-498.

[21] Sidibé, S., Coulibaly, T., Coulibaly, M., et al. (2008) Rôle de l'imagerie dans le diagnostic des lithiases urinaires à l'hôpital du point G. Journal de Radiologie, 89, 1492. https://doi.org/10.1016/S0221-0363(08)76567-3

[22] Derouiche, A., Belhadj, K. and Bouzouita, A. (2010) Place de la néphrolithotomie percutanée dans le traitement des lithiases rénales coralliformes: À propos de 83 cas. La Tunisie Medicale, 88, 5-8.

[23] Traxer, O. (2011) Traitement urologique des lithiases urinaires. Revue du Praticien, 
$61,393$.

[24] Coffi, U. (1995) Contribution à l'étude de la lithiase urinaire chez l'africain au Sénégal à propos de 123 observations. Thèse Med, Dakar, No. 15.

[25] Ekane, S., Wildschutz, T., Simon, J. and Schulman, C.C. (1997) Urinary Lithiasis: Epidemiology and Physiopathology. Acta Urologica Belgica, 65, 1-8. 